\title{
Inhibitory Effect of Flavonoid Extract of Lotus Leaf on Alcohol-Induced Gastric Injury by Antioxidant Capacity in Mice
}

\author{
Yi Chen, ${ }^{1}$ Qin Li, ${ }^{2}$ Zhiping Kuang, ${ }^{3}$ Xin Zhao $\mathbb{D},{ }^{4}$ Ruokun Yi, ${ }^{4}$ Xiaowei He $\mathbb{D},{ }^{1}$ \\ and Guangjing Feng $\mathbb{D}^{1}$ \\ ${ }^{1}$ Department of General Surgery, Chongqing Traditional Chinese Medicine Hospital, Chongqing 400021, China \\ ${ }^{2}$ Department of Ophthalmology, Chongqing Traditional Chinese Medicine Hospital, Chongqing 400021, China \\ ${ }^{3}$ The First Department of Orthopaedic Surgery, Chongqing Traditional Chinese Medicine Hospital, Chongqing 400021, China \\ ${ }^{4}$ Chongqing Collaborative Innovation Center for Functional Food, Chongqing University of Education, Chongqing 400067, China
}

Correspondence should be addressed to Xiaowei He; hexw@cqff.ac.cn and Guangjing Feng; fenggj@cqff.ac.cn

Received 12 February 2020; Accepted 7 March 2020; Published 2 May 2020

Academic Editor: Luca Campone

Copyright ( 92020 Yi Chen et al. This is an open access article distributed under the Creative Commons Attribution License, which permits unrestricted use, distribution, and reproduction in any medium, provided the original work is properly cited.

\begin{abstract}
The aim of this study was to investigate the antioxidant effects of flavonoid extract of lotus leaf (FELL) in vitro and in mice with gastric injury and elucidate the inhibitory effect of FELL on alcohol-induced gastric injury by antioxidant capacity. Gastric juice volume and acid value were measured in the established alcohol-induced acute gastric injury model in mice. Hematoxylin and eosin staining demonstrated the morphological changes in the gastric mucosa. FELL improved the alcohol-induced gastric lesions. Serological testing results showed that FELL significantly increased the levels of superoxide dismutase (SOD), catalase (CAT), glutathione (GSH), and nitric oxide (NO) and significantly reduced the levels of MDA and MPO in mice with gastric injury. Besides, FELL significantly reduced the levels of interleukin 6 (IL-6), interleukin 12 (IL-12), tumor necrosis factor alpha (TNF- $\alpha$ ), and interferon gamma (IFN- $\gamma$ ). The quantitative polymerase chain reaction (qPCR) and Western blot results proved that FELL upregulated the mRNA and protein expressions of SOD1, SOD2, CAT, epidermal growth factor (EGF), vascular endothelial growth factor (VEGF), epidermal growth factor receptor (EGFR), neuronal nitric oxide synthase (nNOS), and endothelial nitric oxide synthase (eNOS) and downregulated the expression of inducible nitric oxide synthase (iNOS) in the gastric tissue of mice with gastric injury. Five compounds, including kaempferitrin, hyperoside, astragalin, phloridzin, and quercetin, were detected in FELL using high-performance liquid chromatography. Thus, FELL has an inhibitory effect on experimental alcohol-induced gastric injury because of the antioxidant capacity of the five compounds. Its effect increases as the FELL concentration increases, which is close to that of ranitidine. FELL, which is an active substance, provides a good gastroprotective effect.
\end{abstract}

\section{Introduction}

Lotus leaves (Nelumbo nucifera Gaertn.) are commonly dried and used for tea and traditional Chinese medicines [1]. Lotus leaf tea is effective for weight loss and gastrointestinal protection, and traditional Chinese medicines made of lotus leaves have also been used for weight loss, lipid reduction, antioxidation, anticonvulsion, and anti-liver fibrosis [2-5]. Because of its multiple effects, lotus leaf has been applied in the development and production of healthy food and has been proved to contain not only carbohydrates, lipids, and proteins that are common in plants but also various bioactive components, the most important of which are flavonoids and alkaloids [6]. The flavonoid extract of lotus leaf (FELL) possesses antioxidative, anti-inflammatory, and lipid regulatory properties through biologically active substances [7-9]. Additionally, lotus leaves have been gradually developed and utilized in a variety of products, such as health drinks, that have entered the market [10]. Thus, lotus leaves and the flavonoids they contain have a very good development and utilization value. The total flavonoids in dried lotus leaves exceed $80 \mathrm{mg} / \mathrm{g}$ [11], showing a potential for its development and utilization.

According to earlier reports, the average annual alcohol intake for adults is about $10 \mathrm{~L}$, which is nearly $14 \mathrm{~L}$ for men [12]. However, recent medical research has confirmed that the 
incidence of gastrointestinal diseases in the drinking population is significantly higher than that in the nondrinking population. Regular intake of high-concentration alcohol will lead to thinning of the gastric mucosa, necrosis and detachment of epithelial cells, injury and embolism in the microvascular endothelium, and ischemic and anoxic necrosis in tissue, resulting in gastric mucosal erosion and ulcer formation, as well as gastroduodenal mucosal damage and related gastropathy [13]. Alcohol causes neutrophil infiltration in the gastric mucosa, releases MPO, oxygen free radicals, active oxidation metabolites such as superoxide anion $\left(\mathrm{O}_{2}{ }^{-}\right)$, and protease, and adheres to the vascular endothelium, producing vascular occlusion and mucosal damage [14]. Free radicals play an important role in the process of alcoholinduced gastric mucosal damage. There are increased levels of lipid peroxides and free radicals in the gastric mucosa of chronic drinkers [15]. Oxygen free radicals on mitochondria act to reduce ATP production, leading to dysfunctional $\mathrm{Na}^{+}$$\mathrm{K}^{+}$-ATPase and elevated $\mathrm{Na}^{+}$concentration in cells, triggering $\mathrm{Na}^{+}-\mathrm{Ca}^{2+}$ exchange, and increasing intracellular calcium. The high calcium level activates phospholipase A2, promotes degradation of phospholipase, and reduces the content of membrane phospholipid. The abnormality in the membrane structure causes an abnormal increase in membrane permeability to $\mathrm{Ca}^{2+}$. Besides, active oxygen can directly inhibit $\mathrm{Ca}^{2+}-\mathrm{Mg}^{2+}$-ATPase, eventually leading to calcium overload. Thus, oxygen free radicals may serve as a trigger for calcium overload, and alcohol-induced gastric mucosal damage may be related to the decreased membrane fluidity caused by intracellular calcium overload and excessive oxygen free radicals [16]. The active substances in natural plants are conducive to the reproduction and the growth of probiotics in the intestine, playing a positive role in promoting the construction of microenvironment in the intestine. Besides, they inhibit the atrophy of the gastric and intestinal mucosa and protect the barrier function of the gastric and intestinal mucosa [17]. Moreover, the active substances in natural plants, especially flavonoids, generally have a good antioxidant effect, endowing them with biological activities on inflammation, cancer, and other diseases [18-20]. So far, there has been no report on the damage of FELL to the murine gastric mucosa. This study aimed to investigate the antioxidant effect of FELL in vitro and its inhibitory effect on alcoholinduced gastric injury in mice using in vitro and in vivo experiments, providing a theoretical basis for the development and the utilization of FELL and the evaluation of its nutritional value.

\section{Materials and Methods}

2.1. Extraction of FELL. For FELL extraction, $300 \mathrm{~g}$ of Anhui lotus leaves was ground and added to a $5 \mathrm{~L}$ beaker with $3 \mathrm{~L}$ of $70 \%$ ethanol at a ratio of $1: 20$. The beaker was sealed with plastic film and heated in a water bath at $60^{\circ} \mathrm{C}$ for $3 \mathrm{~h}$. The mixture in the beaker was then filtered to obtain crude extract of FELL after cooling. FL-3 macroporous resin (Jiangsu Hecheng New Material Co., Ltd., Nanjing, Jiangsu, China) was loaded into a glass column, through which the crude extract was slowly passed. The filtrate passing through the column, for the first time, was discarded, and the column was further eluted with $70 \%$ ethanol until the resin became colorless. The eluted solution was collected in a beaker, followed by rotary evaporation to remove the ethanol in the solution and finally obtain the FELL.

2.2. HPLC. For HPLC analysis, $10 \mathrm{mg}$ FELL was accurately weighed and dissolved in $1 \mathrm{~mL}$ dimethylsulfoxide (DMSO). The components of FELL were detected as follows: C18 column (Agilent Zorbax SB-C, $5 \mu \mathrm{m}, 4.6 \times 250 \mathrm{~mm}$ ); mobile phase $\mathrm{B}, 0.1 \%$ glacial acetic acid; mobile phase $\mathrm{C}$, acetonitrile; column temperature, $35^{\circ} \mathrm{C}$; flow rate, $0.5 \mathrm{~mL} / \mathrm{min}$; detection wavelength, $280 \mathrm{~nm}$; and injection volume, $10 \mu \mathrm{L}$ (UltiMate 3000 high-performance liquid chromatography, Thermo Fisher Scientific, Inc., Waltham, MA, USA).

2.3. Animal Grouping and Treatment. Fifty male Kunming mice (Chongqing Medical University, Chongqing, China) were randomly assigned into five groups $(n=10)$ : normal group, control group, ranitidine group, low-dose FELL group (LFELL, $50 \mathrm{mg} / \mathrm{kg}$ ), and high-dose FELL group (HFELL, $100 \mathrm{mg} / \mathrm{kg}$ ). The mice in the normal group and the control group were given $0.2 \mathrm{~mL}$ of normal saline. Those in the ranitidine group, LFELL group, and HFELL group were given $0.2 \mathrm{~mL}$ of ranitidine $(50 \mathrm{mg} / \mathrm{kg}$ b.w., body weight), FELL extract (50 mg/kg b.w.), and FELL extract (100 mg/kg b.w.), respectively. After gavage on the 14th day, all of the mice had fasted for $24 \mathrm{~h}$, but free water was allowed. On the 15 th day, except for the normal group, the remaining mice were induced gastric injury by gavage (mixture solution of $60 \%$ anhydrous ethanol and $40 \% 150 \mathrm{mmol} / \mathrm{L}$ hydrochloric acid) at a dose of $0.1 \mathrm{~mL} / 10 \mathrm{~g}$ [21]. All of the mice were sacrificed $30 \mathrm{~min}$ after gavage. Blood specimens were collected and centrifuged at $4^{\circ} \mathrm{C}$ at $4,000 \mathrm{r} / \mathrm{min}$ for $10 \mathrm{~min}$ to collect the upper serum specimens. The entire stomach, $1.5 \mathrm{~cm}$ from the cardia to the pylorus, was removed. The gastric juice was collected, and the $\mathrm{pH}$ of the gastric juice was measured. The stomach was opened along the greater curvature, washed with iced physiological saline, and photographed. The damage area of the gastric mucosa and the inhibition rate of gastric injury were calculated using Image J software. The gastric tissue of $1 \mathrm{~cm} \times 0.5 \mathrm{~cm}$ was fixed in $10 \%$ formalin solution for pathological section. The protocol for these experiments was approved by the Animal Ethics Committee of Chongqing Collaborative Innovation Center for Functional Food, and the animal permit number is 201910025B.

2.4. Measurements of Serum SOD, CAT, GSH, NO, and MDA. Plasma was separated by centrifugation at 4,000 $\mathrm{r} / \mathrm{min}$ for $10 \mathrm{~min}$. The serum levels of SOD, CAT, GSH, NO, and MDA were measured using kits (Nanjing Jiancheng Bioengineering Institute, Nanjing, Jiangsu, China).

2.5. Measurements of Serum IL-6, IL-12, TNF- $\alpha$, and IFN- $\gamma$. The serum levels of SOD, CAT, GSH, NO, MDA, and MPO were measured by kits (Nanjing Jiancheng Bioengineering Institute). 
2.6. Observation of Sections. The gastric tissue was fixed in $10 \%$ formalin solution for $48 \mathrm{~h}$, dehydrated, cleared, waxed, embedded, sectioned, and stained with hematoxylin and eosin (H\&E). The morphological changes in the tissues were observed using an optical microscope (BX43 optical microscope, Olympus, Tokyo, Japan).

\subsection{Measurement of Related mRNA Expression in the Gastric} Tissue. Portions of the left and right gastric tissue (50 mg) were homogenized, from which the total RNA was extracted by Trizol (Thermo Fisher Scientific, Inc., Waltham, MA, USA) and measured using a microspectrophotometer (Nano-300, Hangzhou Allsheng Instruments Co., Ltd, Hangzhou, Zhejiang, China). The RNA solution was further diluted to $1 \mu \mathrm{g} / \mathrm{mL}$. We added $1 \mu \mathrm{L}$ of oligo Primer dT to $1 \mu \mathrm{L}$ of RNA solution $(1 \mu \mathrm{g} / \mu \mathrm{L})$ and $10 \mu \mathrm{L}$ of sterile ultrapure water, reacted at $65^{\circ} \mathrm{C}$ for $5 \mathrm{~min}$, and then mixed well with $4 \mu \mathrm{L}$ of reaction buffer, $1 \mu \mathrm{L}$ of Riblock RNase Inhibitor, and $2 \mu \mathrm{L}$ of dNTP, followed by the addition of $1 \mu \mathrm{L}$ of Revert Aid M-mu/v RT (Thermo Fisher Scientific) for synthesis of cDNA at $42^{\circ} \mathrm{C}$ for $60 \mathrm{~min}$ and $70^{\circ} \mathrm{C}$ for $5 \mathrm{~min}$. We added $10 \mu \mathrm{L}$ of Master, $1 \mu \mathrm{L}$ of upstream primer, $1 \mu \mathrm{L}$ of downstream primer, $1 \mu \mathrm{L}$ of cDNA template, and $7 \mu \mathrm{L}$ of sterilized ultrapure water into an eight-well PCR strip, mixed, and centrifuged. The amplification conditions (StepOne Plus, Thermo Fisher Scientific) were as follows: denaturation at $95^{\circ} \mathrm{C}$ for $15 \mathrm{~min}$, annealing at $60^{\circ} \mathrm{C}$ for $1 \mathrm{~h}$, extension at $95^{\circ} \mathrm{C}$ for $15 \mathrm{~min}, 40$ cycles. Taking GAPDH as the internal reference gene, the relative expression of each gene was calculated by $2^{-\Delta \Delta C T}$ [22]. The corresponding gene primer sequence is shown in Table 1.

2.8. Data Process. All of the data are expressed as mean\pm standard deviation values. One-way analysis of variance was used to analyze the differences (SPSS17.0 software). A $P<0.05$ was considered to be statistically significant.

\section{Results}

3.1. Components of FELL. As shown in Figure 1, FELL mainly contains five chemicals, including kaempferitrin, hyperoside, astragalin, phloridzin, and quercetin at 478.51 , $232.74,12.62,5.67$, and $0.49 \mathrm{mg} / \mathrm{g}$, respectively.

3.2. Gastric Juice Volume and Gastric Acid Value. Table 2 shows that the gastric juice volume of the control group is the highest, and that of the mice fed with FELL, regardless of concentration, is significantly lower than that of the control group $(P<0.05)$. The gastric juice volume of the mice in the HFELL group is close to that of the normal group and the ranitidine group. The $\mathrm{pH}$ of gastric juice is significantly lower in the other groups than in the control group $(P<0.05)$.

3.3. Inhibition of Gastric Mucosal Damage in Mice. Figure 2 and Table 3 show the largest gastric mucosal damage area in the control group. After administration of
TABLE 1: Sequences of primers used in the qPCR assay.

\begin{tabular}{|c|c|}
\hline Gene & Sequence \\
\hline $\begin{array}{l}\mathrm{SOD} 1 \\
(\mathrm{Cu} / \\
\mathrm{Zn}-\mathrm{SOD})\end{array}$ & $\begin{array}{c}\text { Forward: } 5^{\prime} \text {-AACCAGTTGTGTTGTCAGGAC-3' } \\
\text { Reverse: } 5^{\prime} \text {-CCACCATGTTTCTTAGAGTG } \\
\text { AGG-3' }\end{array}$ \\
\hline SOD2 & $\begin{array}{l}\text { Forward: } 5^{\prime} \text {-CAGACCTGCCTTACGACTATGG- } \\
\qquad 3^{\prime}\end{array}$ \\
\hline$(\mathrm{Mn}-\mathrm{SOD})$ & Reverse: $5^{\prime}$-CTCGGTGGCGTTGAGATTGTT-3' \\
\hline CAT & $\begin{array}{l}\text { Forward: } 5^{\prime} \text {-GGAGGCGGGAACCCAATAG- } 3^{\prime} \\
\text { Reverse: } 5^{\prime} \text {-GTGTGCCATCTCGTCAGTGAA-3' }\end{array}$ \\
\hline EGF & $\begin{array}{l}\text { Forward: } 5^{\prime} \text {-TGGGTCTCGGATTGGGCT-3' } \\
\text { Reverse: } 5^{\prime} \text {-ACCACAACCAGTGACGAGGG-3' } \\
\text { Forward: } 5^{\prime} \text {-GCCATCTGGGCCAAAGATACC- }\end{array}$ \\
\hline EGFR & 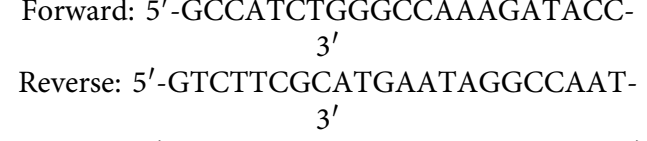 \\
\hline VEGF & $\begin{array}{l}\text { Forward: } 5^{\prime} \text {-TCGTCCAACTTCTGGGCTCTT-3' } \\
\text { Reverse: } 5^{\prime} \text {-CCTTCTCTTCCTCCCCTCTCTTC- } \\
\qquad 3^{\prime}\end{array}$ \\
\hline iNOS & $\begin{array}{c}\text { Forward: 5'-AGAGAGATCGGGTTCACA-3' } \\
\text { Reverse: } 5^{\prime} \text {-CACAGAACTGAGGGTACA-3' } \\
\text { Forward: } 5^{\prime} \text {-TCGTCCAACTTCTGGGCTCTT-3' }\end{array}$ \\
\hline nNOS & 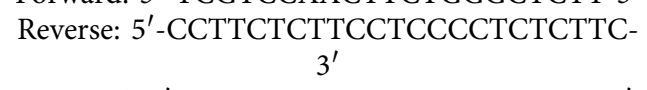 \\
\hline eNOS & $\begin{array}{l}\text { Forward: } 5^{\prime} \text {-TCAGCCATCACAGTGTTCCC-3' } \\
\text { Reverse: } 5^{\prime} \text {-ATAGCCCGCATAGCGTATCAG-3' } \\
\text { Forward: } 5^{\prime} \text {-AGGTCGGTGTGAACGGATTTG- }\end{array}$ \\
\hline GAPDH & $\begin{array}{c}3^{\prime} \\
\text { Reverse: } 5^{\prime} \text {-GGGGTCGTTGATGGCAACA-3' }\end{array}$ \\
\hline
\end{tabular}

FELL and ranitidine, the damage area decreases. Calculation reveals that the inhibition rate of HFELL on gastric injury is significantly higher than that of LFELL, which is close to that of ranitidine.

3.4. Histopathology. After H\&E staining, the histopathological changes of the gastric tissue were observed under an optical microscope. As shown in Figure 3, the gastric mucosa of normal mice is nearly free of rupture or damage, the glands are arranged orderly, and no inflammatory cell infiltration in the lamina propria mucosae is observed, indicating that saline by gavage cannot cause injury to the gastric mucosa. Compared with the normal group, the model group represents serious rupture and detachment of gastric mucosa, disordered arrangement of glands, and serious inflammatory cell infiltration of the lamina propria, suggesting successful modeling of gastric mucosal injury. The gastric mucosa in the FELL and ranitidine groups shows pathological damage in different degrees, but better than in the model group. Similar to ranitidine, HFELL has a better inhibitory effect on the gastric mucosal damage. The epithelial cells of the gastric mucosa are nearly complete, and the glands are arranged orderly with lower secretion of inflammatory cells.

3.5. Measurements of Serum SOD, CAT, GSH, NO, and MDA. In Table 4, compared with the normal group, the SOD, CAT, GSH, and NO levels in the control group are significantly reduced $(P<0.05)$, and the MDA level is 


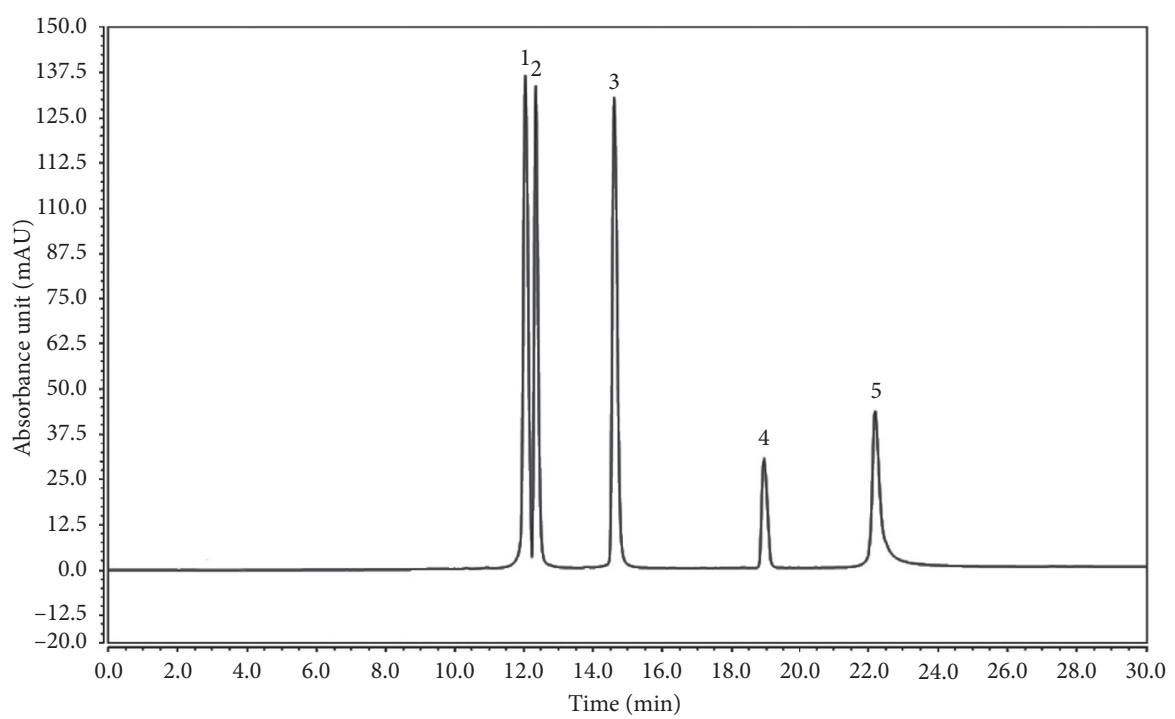

(a)

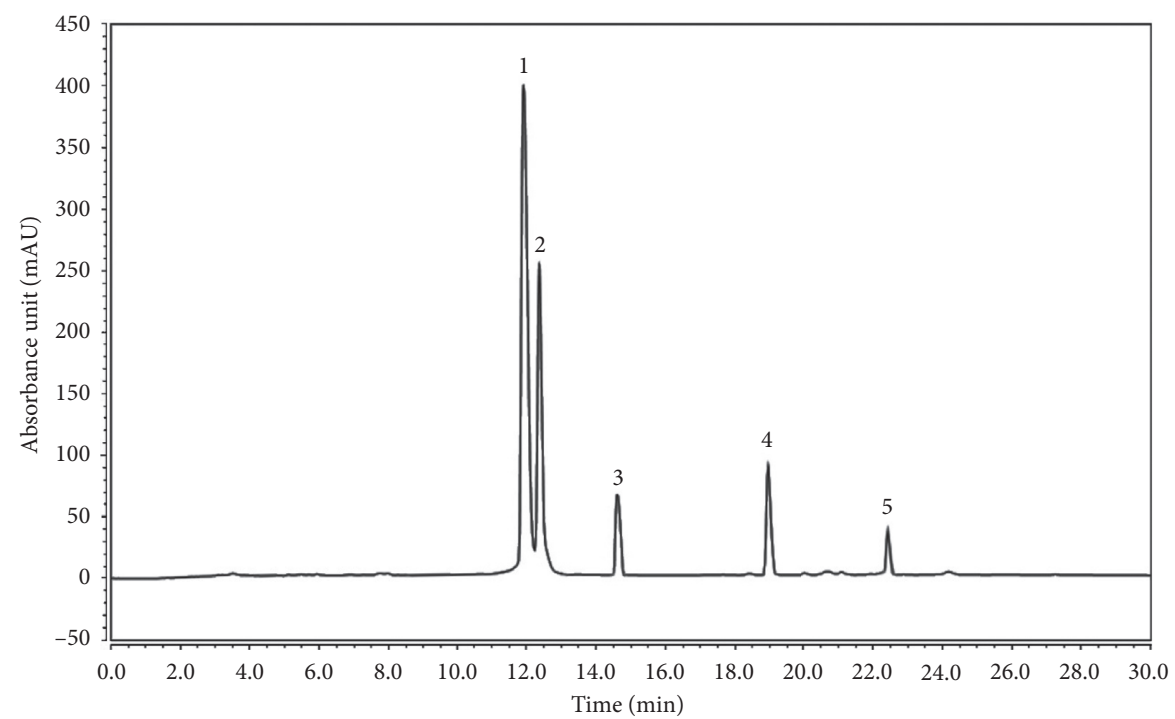

(b)

Figure 1: Liquid chromatogram of (a) standard products and (b) flavonoid extract of lotus leaf. (1) Kaempferitrin, (2) hyperoside, (3) astragalin, (4) phloridzin, and (5) quercetin.

TABLE 2: Gastric secretion volume and $\mathrm{pH}$ of gastric juice in mice with gastric injury.

\begin{tabular}{lcc}
\hline Group & Gastric secretion volume $(\mathrm{mL})$ & $\mathrm{pH}$ of gastric juice \\
\hline Normal & $0.10 \pm 0.01^{\mathrm{d}}$ & $4.80 \pm 0.13^{\mathrm{a}}$ \\
Control & $0.29 \pm 0.02^{\mathrm{a}}$ & $1.72 \pm 0.15^{\mathrm{e}}$ \\
Ranitidine & $0.16 \pm 0.01^{\mathrm{c}}$ & $4.02 \pm 0.11^{\mathrm{b}}$ \\
LFELL & $0.22 \pm 0.02^{\mathrm{b}}$ & $2.54 \pm 0.22^{\mathrm{d}}$ \\
HFELL & $0.17 \pm 0.02^{\mathrm{c}}$ & $3.60 \pm 0.14^{\mathrm{c}}$ \\
\hline
\end{tabular}

${ }^{\mathrm{a}-\mathrm{b}}$ Mean values with different letters in the same column are significantly different $(P<0.05)$ according to Duncan's new MRT. The ranitidine group, $50 \mathrm{mg} / \mathrm{kg}$ b.w. ranitidine treatment dose; the LLTP group, $50 \mathrm{mg} / \mathrm{kg}$ b.w. flavonoid extract of lotus leaf dose; and the HLTP group, $100 \mathrm{mg} / \mathrm{kg}$ b.w. flavonoid extract of lotus leaf. significantly increased $(P<0.05)$. Compared with the model group, the serum levels of SOD, CAT, GSH, and NO in the FELL groups are significantly increased $(P<0.05)$, but the serum MDA level in the FELL group is significantly lower than that of the control group $(P<0.05)$. The serum levels of SOD, CAT, GSH, NO, and MDA in the HFELL group are closer to those in the normal group and the ranitidine group.

3.6. Measurements of Serum IL-6, IL-12, TNF- $\alpha$, and IFN- $\gamma$. As shown in Table 5, the levels of IL-6, IL-12, TNF- $\alpha$, and IFN- $\gamma$ in the normal group are the lowest, but those in the 


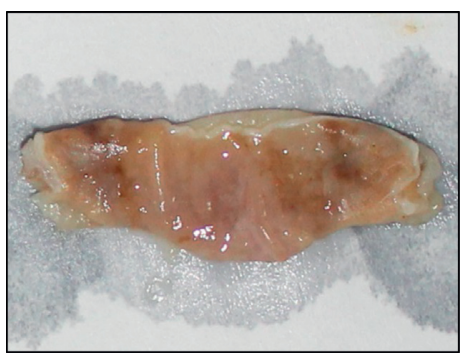

(a)

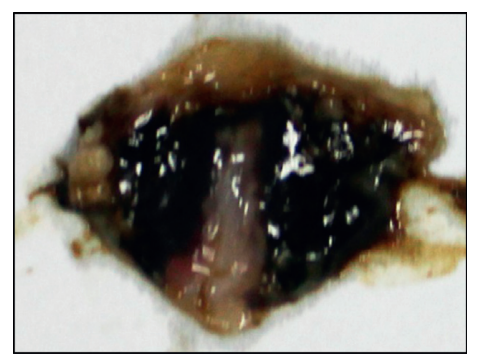

(b)

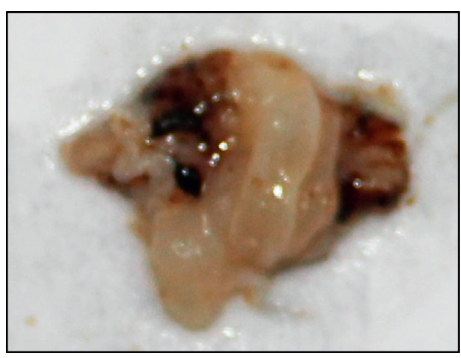

(c)

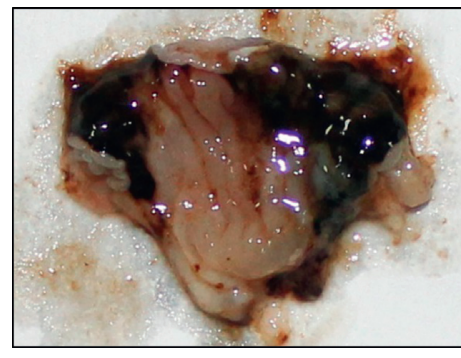

(d)

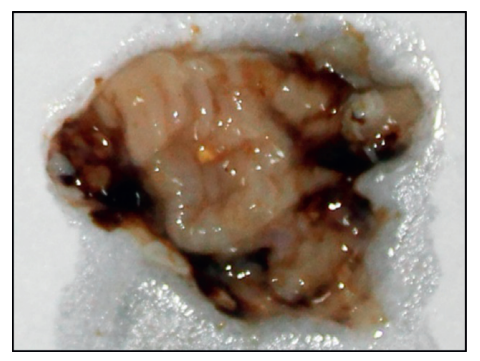

(e)

FIgURE 2: Observation of gastric mucosa in mice with gastric injury. The ranitidine group, $50 \mathrm{mg} / \mathrm{kg}$ b.w. ranitidine treatment dose; the LLTP group, $50 \mathrm{mg} / \mathrm{kg}$ b.w. flavonoid extract of lotus leaf dose; and the HLTP group, $100 \mathrm{mg} / \mathrm{kg}$ b.w. flavonoid extract of lotus leaf. (a) Normal. (b) Control. (c) Ranitidine. (d) LFELL. (e) HFELL.

TABLE 3: Gastric injury area and inhibition rate of gastric injury in mice.

\begin{tabular}{lcc}
\hline Group & Gastric injury area $\left(\mathrm{mm}^{2}\right)$ & Gastric injury inhibitory rate (\%) \\
\hline Normal & $0.00 \pm 0.00^{\mathrm{e}}$ & $100.00 \pm 0.00^{\mathrm{a}}$ \\
Control & $29.86 \pm 1.22^{\mathrm{a}}$ & - \\
Ranitidine & $6.53 \pm 0.42^{\mathrm{d}}$ & $78.08 \pm 1.99^{\mathrm{b}}$ \\
LFELL & $17.06 \pm 1.89^{\mathrm{b}}$ & $42.94 \pm 5.01^{\mathrm{d}}$ \\
HFELL & $7.75 \pm 0.34^{\mathrm{c}}$ & $74.04 \pm 1.32^{\mathrm{c}}$ \\
\hline
\end{tabular}

${ }^{\mathrm{a}-\mathrm{e}}$ Mean values with different letters in the same column are significantly different $(P<0.05)$ according to Duncan's new MRT. The ranitidine group, $50 \mathrm{mg} / \mathrm{kg}$ b.w. ranitidine treatment dose; the LLTP group, $50 \mathrm{mg} / \mathrm{kg}$ b.w. flavonoid extract of lotus leaf dose; and the HLTP group, $100 \mathrm{mg} / \mathrm{kg}$ b.w. flavonoid extract of lotus leaf.

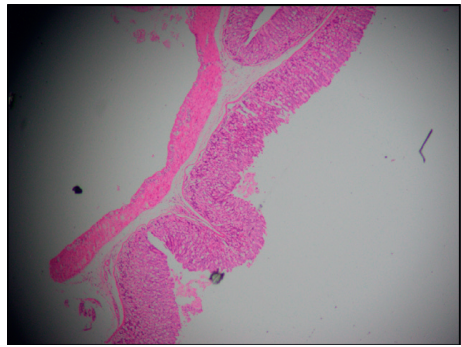

(a)

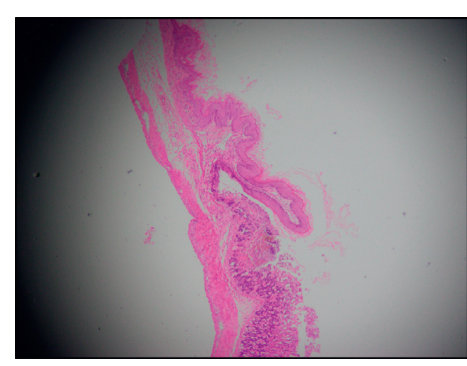

(d)

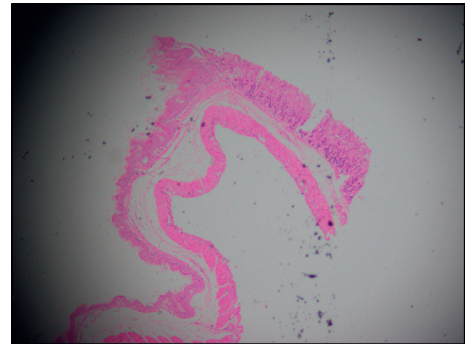

(b)

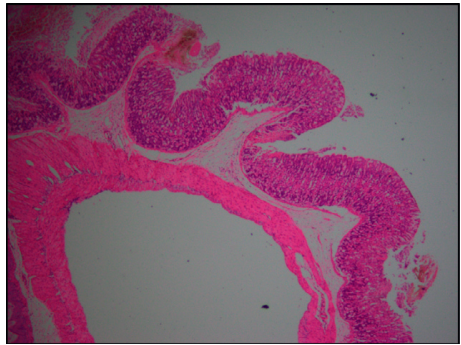

(c)

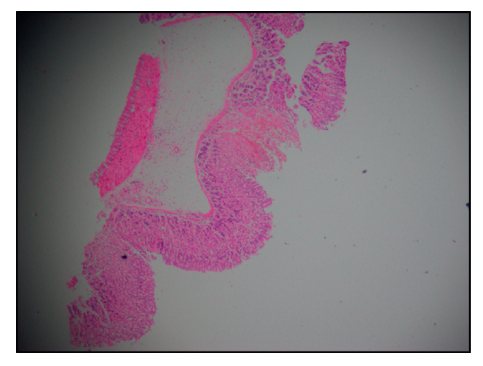

(e)

Figure 3: H\&E staining pathological observation of gastric mucosa in mice with gastric injury. The ranitidine group, $50 \mathrm{mg} / \mathrm{kg}$ b.w. ranitidine treatment dose; the LLTP group, $50 \mathrm{mg} / \mathrm{kg}$ b.w. flavonoid extract of lotus leaf dose; and the HLTP group, $100 \mathrm{mg} / \mathrm{kg}$ b.w. flavonoid extract of lotus leaf. (a) Normal. (b) Control. (c) Ranitidine. (d) LFELL. (e) HFELL. 
TABle 4: Serum SOD, CAT, GSH, NO, and MDA levels in mice with gastric injury.

\begin{tabular}{lccccc}
\hline Group & SOD $(\mathrm{U} / \mathrm{mL})$ & CAT $(\mathrm{U} / \mathrm{mL})$ & GSH $(\mu \mathrm{mol} / \mathrm{L})$ & NO $(\mu \mathrm{mol} / \mathrm{L})$ & MDA $(\mu \mathrm{mol} / \mathrm{L})$ \\
\hline Normal & $139.52 \pm 6.07^{\mathrm{a}}$ & $36.36 \pm 2.02^{\mathrm{a}}$ & $12.87 \pm 0.30^{\mathrm{a}}$ & $104.11 \pm 4.84^{\mathrm{a}}$ & $5.92 \pm 0.17^{\mathrm{e}}$ \\
Control & $74.42 \pm 4.34^{\mathrm{e}}$ & $11.76 \pm 0.67^{\mathrm{e}}$ & $7.12 \pm 0.30^{\mathrm{e}}$ & $73.13 \pm 2.71^{\mathrm{e}}$ & $14.90 \pm 0.51^{\mathrm{a}}$ \\
Ranitidine & $116.26 \pm 3.73^{\mathrm{b}}$ & $27.02 \pm 1.01^{\mathrm{b}}$ & $11.22 \pm 0.36^{\mathrm{b}}$ & $90.66 \pm 1.24^{\mathrm{b}}$ & $8.25 \pm 0.31^{\mathrm{d}}$ \\
LFELL & $87.95 \pm 3.92^{\mathrm{d}}$ & $18.54 \pm 0.78^{\mathrm{d}}$ & $8.56 \pm 0.20^{\mathrm{d}}$ & $77.96 \pm 1.54^{\mathrm{d}}$ & $12.21 \pm 0.43^{\mathrm{b}}$ \\
HFELL & $102.27 \pm 6.04^{\mathrm{c}}$ & $25.32 \pm 0.60^{\mathrm{c}}$ & $9.36 \pm 0.25^{\mathrm{c}}$ & $85.75 \pm 1.43^{\mathrm{c}}$ & $9.68 \pm 0.28^{\mathrm{c}}$ \\
\hline
\end{tabular}

${ }^{\mathrm{a}-\mathrm{e}}$ Mean values with different letters in the same column are significantly different $(P<0.05)$ according to Duncan's new MRT. The ranitidine group, $50 \mathrm{mg} / \mathrm{kg}$ b.w. ranitidine treatment dose; the LLTP group, $50 \mathrm{mg} / \mathrm{kg}$ b.w. flavonoid extract of lotus leaf dose; and the HLTP group, $100 \mathrm{mg} / \mathrm{kg}$ b.w. flavonoid extract of lotus leaf.

control group are the highest. Under the effects of FELL and ranitidine, the levels of these cytokines in the gastric injury mice decrease. The capability of HFELL reducing these inflammatory cytokines is higher than that of LFELL, and slightly lower than that of ranitidine.

\section{7. $m R N A$ Expression of SOD1, SOD2, and CAT in the Gastric} Tissue. Figure 4 illustrates that mRNA and protein expressions of SOD1, SOD2, and CAT in the gastric tissue of mice after alcohol-induced gastric injury are lower than those of normal mice. After the gastric injury mice were administered FELL and ranitidine, the expressions of SOD1, SOD2, and CAT increased. The ability of HFELL upregulating the expression is greater than LFELL but slightly lower than ranitidine.

3.8. $m R N A$ Expression of EGF, VEGF, and EGFR in the Gastric Tissue. As shown in Figure 5, the expressions of EGF, VEGF, and EGFR are the lowest in the control group and the highest in the normal group. The expression in the gastric tissues of mice in the ranitidine group, LFELL group, and HFELL group is higher than that in the control group. Besides, the expression is higher in the HFELL group than in the LFELL group but lower than that in the ranitidine group.

3.9. $m R N A$ Expression of $n N O S$, eNOS, and iNOS in the Gastric Tissue. As shown in Figure 6, the expressions of eNOS and nNOS are the highest in the normal group, but the expression of iNOS is the lowest. Compared with the normal group, the expressions of eNOS and nNOS in the control group are significantly reduced $(P<0.05)$, and that of iNOS is significantly increased $(P<0.05)$. Compared with the control group, the expressions of eNOS and nNOS increase in the gastric tissues of the LFELL, HFELL, and ranitidine groups, but that of iNOS decreases significantly $(P<0.05)$. The expressions of nNOS, eNOS, and iNOS in the gastric tissues of the HFELL and ranitidine groups are closer to those of the normal group.

\section{Discussion}

Alcohol (ethanol) has a significant effect on the gastric mucosa and is closely related to various gastric mucosal diseases. Alcohol-induced gastric mucosal damage is observed more commonly in the clinic. The carbon-oxygen bond and hydrogen-oxygen bond in alcohol molecules can easily rupture, resulting in oxidation reaction, which can cause gastric mucosal damage [23]. Flavonoids can improve antioxidant and free radical scavenging capability in animals. The hydrogen atoms on the phenolic hydroxyl group can bind with the peroxy radicals to form flavonoid free radicals and react with other free radicals to terminate the free-radical chain reaction [24]. Ranitidine is one of the most widely used drugs in the treatment of ulcerative diseases. It can effectively inhibit the secretion of gastric acid and reduce the activity of gastric acid and gastric enzyme. It is mainly used in the treatment of excessive gastric acid and gastric ulcer [25]. Therefore, ranitidine was used as a drug positive control in the study and compared with the FELL.

Too much secretion or too low $\mathrm{pH}$ of gastric juice will aggravate gastric injury [26]. Thus, FELL can reduce excessive secretion and maintain a normal $\mathrm{pH}$ value of gastric juice and decrease to a certain extent the acute injury effect of high-concentration alcohol on the stomach.

Increasingly, more studies have reported that the alcohol-induced gastric injury is related to the elevated level of active oxygen in the body [27]. There are enzyme and nonenzyme antioxidant defense systems in the body, including SOD, GSH, and CAT. SOD, GSH, and CAT have been proven to scavenge superoxide, hydrogen peroxide, hydroxyl, and lipid hydrogen peroxide radicals, thus reducing the oxidative damage of tissues [28]. In particular, SOD1 (Cu/Zn-SOD) in the cytoplasm of eukaryotic cells and SOD2 (Mn-SOD) in mitochondria play important roles in the process of oxidative stress in the body. Regulating these two SOD enzymes can effectively maintain oxidative balance in the body and reduce the damage [29]. MDA is an indicator to evaluate lipid peroxidation, and its content is positively related to the degree of cell injury. When the content of reactive oxygen in the body exceeds the scavenging capability of the antioxidant defense system, the gastrointestinal immune function will be seriously damaged by free radicals, resulting in tissue and organ damage [30]. Exogenous NO has been proven to reduce the damage of alcohol to the gastric mucosa without excessive NO, but the endogenous NO can scavenge oxygen free radicals and reduce the degree of acute gastric mucosal damage, suggesting a protective effect of NO on the gastric mucosa [31]. Serological parameters indicate that FELL can regulate the oxidation degree in mice with gastric injury and, thus, inhibit gastric injury by reducing oxidation. 
TABLE 5: Serum cytokine IL-6, IL-12, TNF- $\alpha$, and IFN- $\gamma$ levels in gastric tissue of mice with gastric injury.

\begin{tabular}{lcccc}
\hline Group & IL-6 $(\mathrm{pg} / \mathrm{mL})$ & IL-12 $(\mathrm{pg} / \mathrm{mL})$ & TNF- $\alpha(\mathrm{pg} / \mathrm{mL})$ & IFN- $\gamma(\mathrm{pg} / \mathrm{mL})$ \\
\hline Normal & $44.61 \pm 3.97^{\mathrm{e}}$ & $204.87 \pm 6.75^{\mathrm{e}}$ & $25.22 \pm 1.65^{\mathrm{e}}$ & $18.81 \pm 1.95^{\mathrm{e}}$ \\
Control & $233.77 \pm 4.52^{\mathrm{a}}$ & $769.08 \pm 23.45^{\mathrm{a}}$ & $90.73 \pm 1.93^{\mathrm{a}}$ & $78.32 \pm 2.49^{\mathrm{a}}$ \\
Ranitidine & $68.39 \pm 5.52^{\mathrm{d}}$ & $381.32 \pm 22.77^{\mathrm{d}}$ & $41.44 \pm 1.71^{\mathrm{d}}$ & $29.13 \pm 1.73^{\mathrm{d}}$ \\
LFELL & $167.97 \pm 11.62^{\mathrm{b}}$ & $623.48 \pm 29.18^{\mathrm{b}}$ & $74.10 \pm 1.34^{\mathrm{b}}$ & $60.61 \pm 4.34^{\mathrm{b}}$ \\
HFELL & $76.07 \pm 3.72^{\mathrm{c}}$ & $458.22 \pm 18.23^{\mathrm{c}}$ & $54.46 \pm 3.07^{\mathrm{c}}$ & $36.51 \pm 2.72^{\mathrm{c}}$ \\
\hline
\end{tabular}

${ }^{a-e}$ Mean values with different letters in the same column are significantly different $(P<0.05)$ according to Duncan's new MRT. The ranitidine group, $50 \mathrm{mg} / \mathrm{kg}$ b.w. ranitidine treatment dose; the LLTP group, $50 \mathrm{mg} / \mathrm{kg}$ b.w. flavonoid extract of lotus leaf dose; and the HLTP group, $100 \mathrm{mg} / \mathrm{kg}$ b.w. flavonoid extract of lotus leaf.

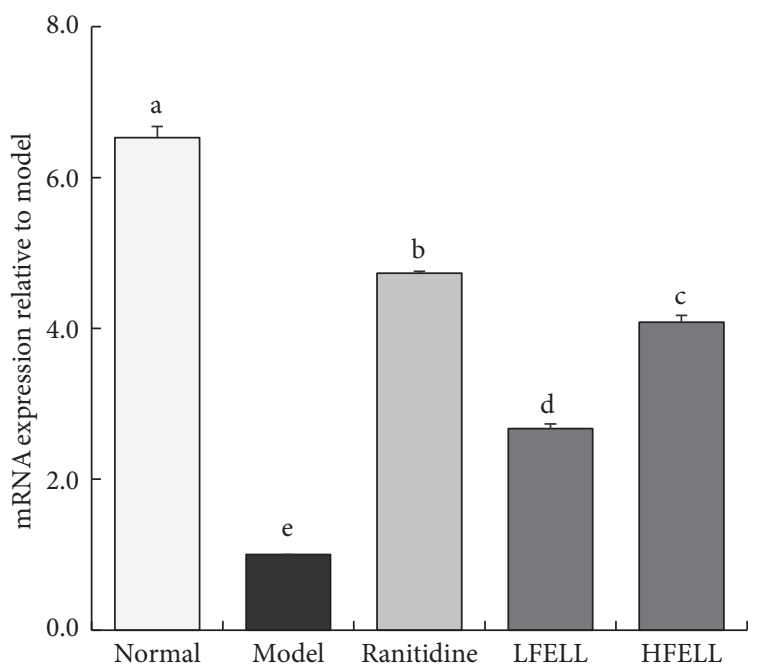

(a)

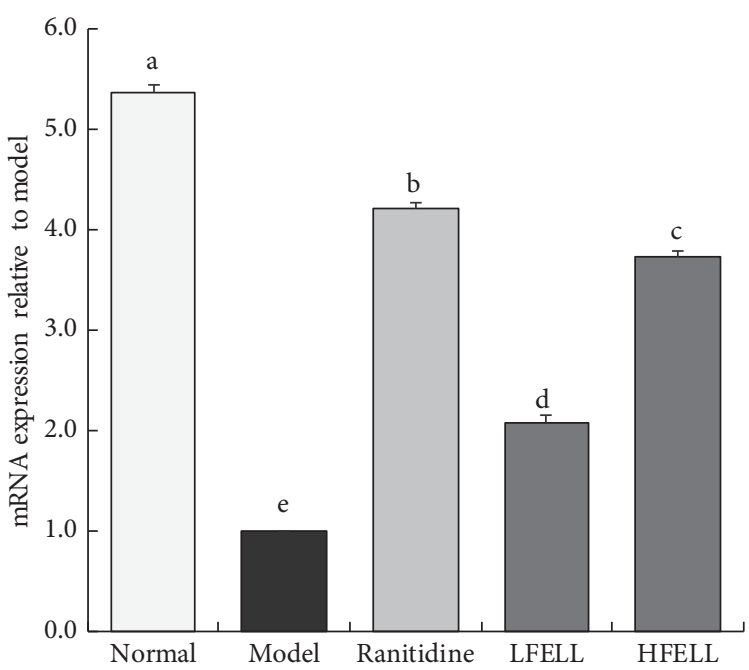

(b)

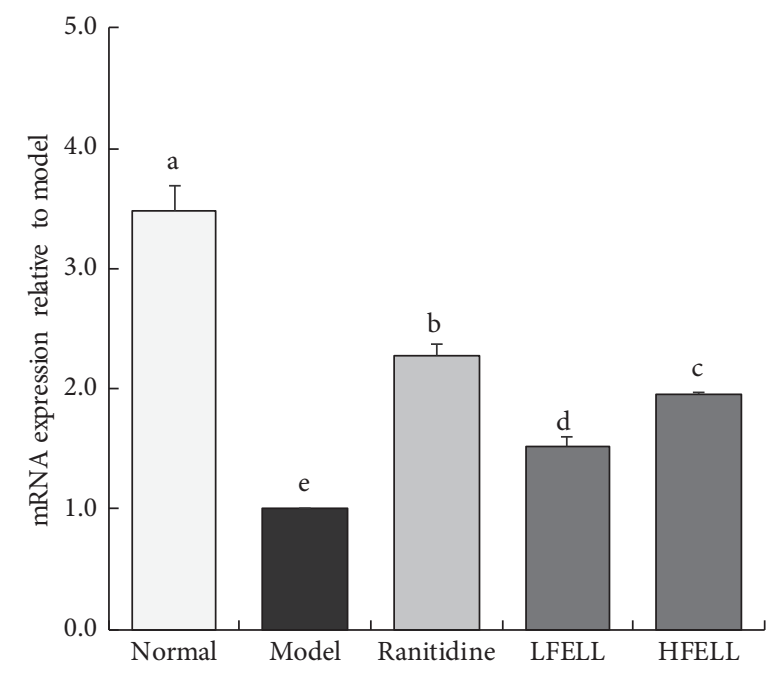

(c)

Figure 4: The mRNA expression of SOD1, SOD2, CAT, and GSH in the gastric tissue of mice. Values presented are the mean \pm standard deviation. ${ }^{a-c}$ Mean values with different letters in the bar are significantly different $(P<0.05)$ according to Duncan's new MRT. The ranitidine group, $50 \mathrm{mg} / \mathrm{kg}$ b.w. ranitidine treatment dose; the LLTP group, $50 \mathrm{mg} / \mathrm{kg}$ b.w. flavonoid extract of lotus leaf dose; and the HLTP group, $100 \mathrm{mg} / \mathrm{kg}$ b.w. flavonoid extract of lotus leaf. (a) SOD1. (b) SOD2. (c) CAT.

The EGF can thicken the cell wall of mucosal cells when the mucosa is damaged so that it can better resist tissue damage caused by oxidative stress, prevent further expansion of the damage area, and accelerate the growth of mucosal cells (epithelial cells on the surface of the stomach, cervical mucosal cells in the secreting acid glands, cardiac gland cells, and pyloric gland cells). After the gastric environment is considerably improved by the EGF, the mucosal 


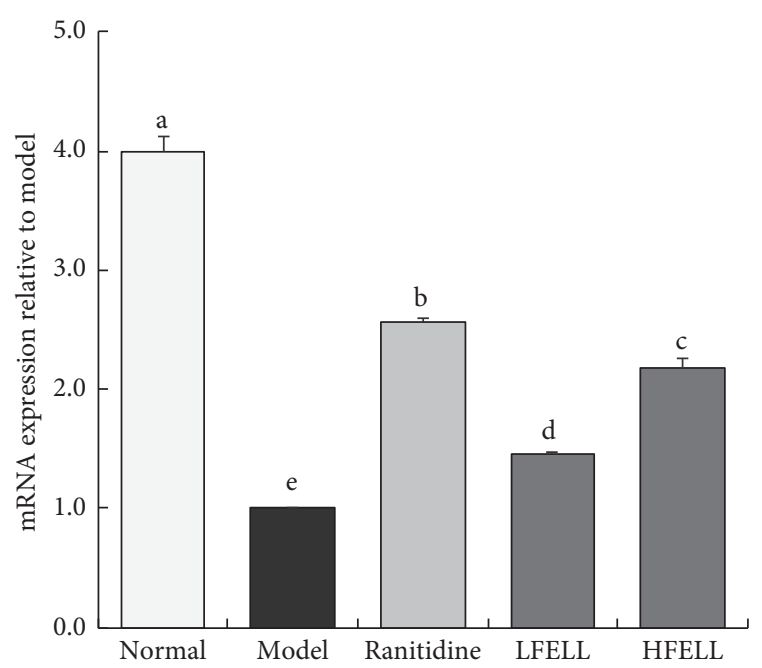

(a)

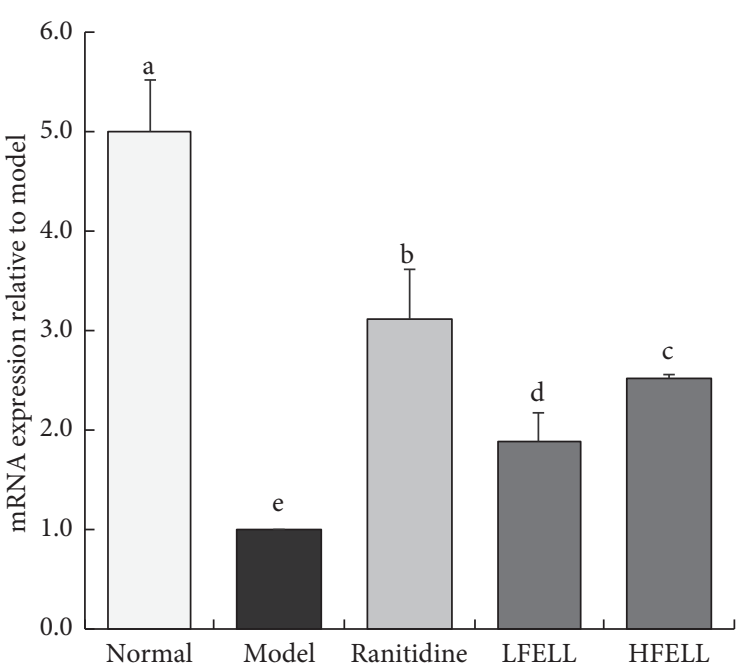

(b)

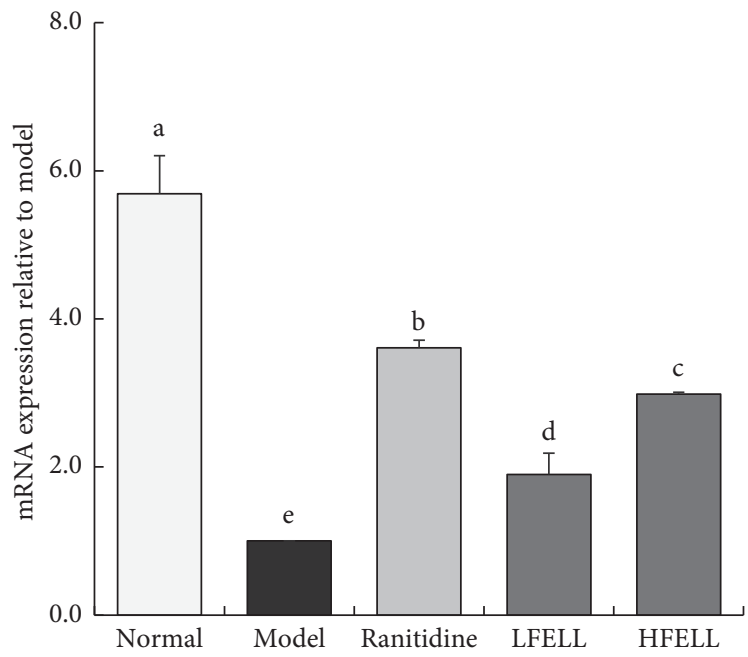

(c)

FIGURE 5: The mRNA expression of EGF, VEGF, and EGFR in the gastric tissue of mice. Values presented are the mean \pm standard deviation. ${ }^{a-c}$ Mean values with different letters in the bar are significantly different $(P<0.05)$ according to Duncan's new MRT. The ranitidine group, $50 \mathrm{mg} / \mathrm{kg}$ b.w. ranitidine treatment dose; the LLTP group, $50 \mathrm{mg} / \mathrm{kg}$ b.w. flavonoid extract of lotus leaf dose; and the HLTP group, $100 \mathrm{mg} / \mathrm{kg}$ b.w. flavonoid extract of lotus leaf. (a) EGF. (b) EGFR. (c) VEGF.

cells fully grow again and rapidly build new gastric mucosa [32]. VEGF stimulation on vascular endothelial cells can increase the content of NO, thus promoting oxidative stressinduced gastric tissue lesions [33]. The EGFR is located on the surface of the cell membrane and is activated by binding ligands, including EGF and TGF- $\alpha$. The EGFR can affect angiogenesis by regulating Ang-1 and VEGF [34]. Besides, it can be stimulated in the lesion of the body caused by oxidative stress, leading to signal transduction, which plays a role in tissue repair [35]. Thus, FELL enhances alcoholinduced gastric tissue repair via EGF, VEGF, and EGFR.

There are two types of NOS in the gastric mucosa: constitutive NOS (cNOS, including eNOS and nNOS) and inducible NOS (iNOS). cNOS catalyzes production of an appropriate amount of $\mathrm{NO}$, with a protective effect on the gastric mucosa to a certain extent. Moreover, the occurrence of gastric ulcer is related to excessive inhibition on eNOS and
nNOS. Inhibiting the decreased expressions of eNOS and nNOS in the gastric tissues plays a better protective role in the alcohol-induced gastric injury [36]. When the body is stimulated by oxidants and other toxic substances to generate oxidative stress, some endotoxins and cytokines will stimulate the expression of iNOS. Reducing the iNOS expression can effectively alleviate the degree of gastric injury [37]. This study also proved that FELL could regulate the expression of NOS in the gastric tissues and inhibit gastric injury.

Kaempferitrin is a natural flavonoid glycoside, with analgesic, anti-inflammatory, antidiabetic, and antitumor properties, and it has also been used as chemotherapy. Other plants with high kaempferitrin content also protect the liver [38]. Hyperoside is an important natural product with multiple physiological activities and has been observed to be anti-inflammatory, reduce cholesterol, relieve pain in the 


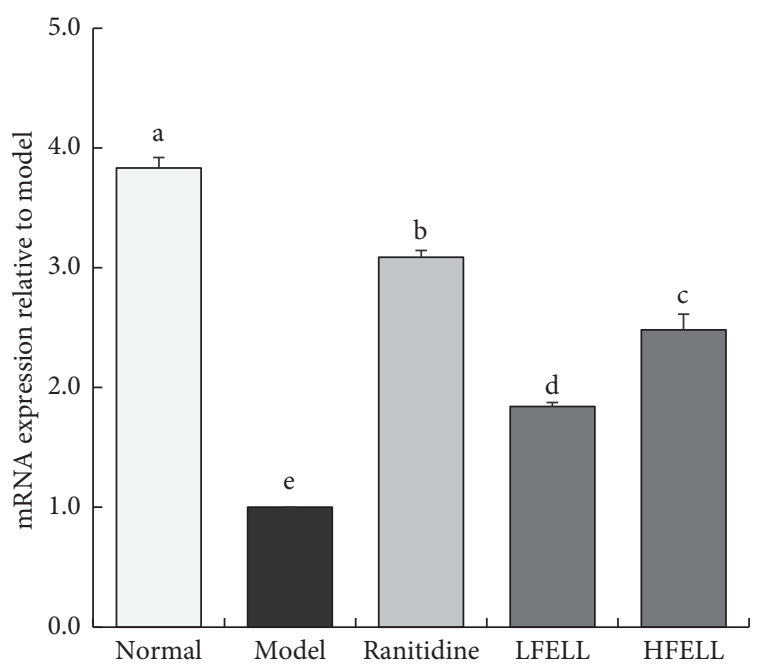

(a)

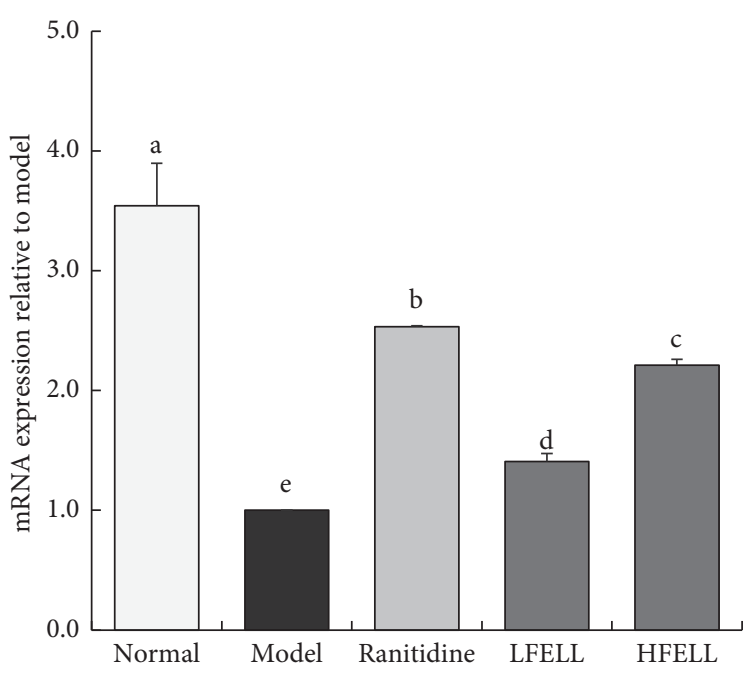

(b)

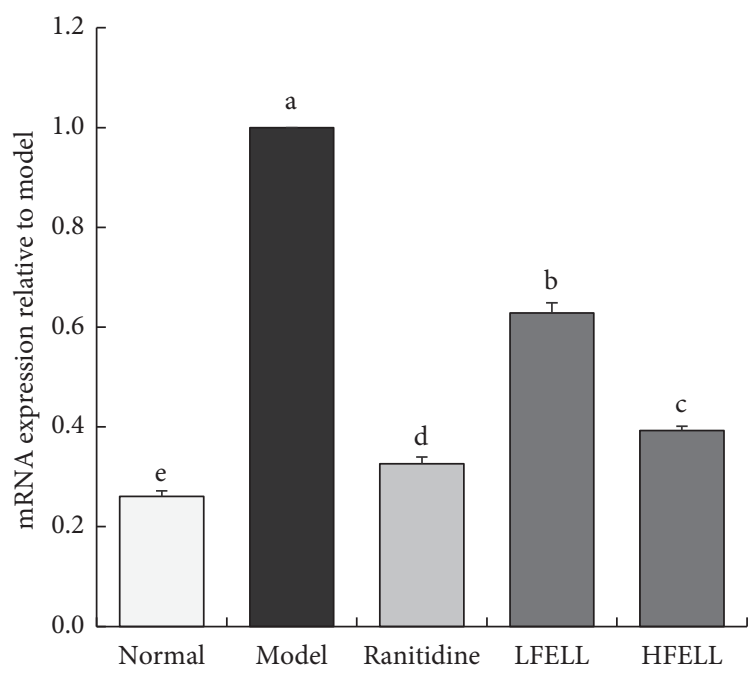

(c)

FIGURE 6: The mRNA expression of EGF, VEGF, and EGFR in the gastric tissue of mice. Values presented are the mean \pm standard deviation. ${ }^{\mathrm{a}-\mathrm{c}}$ Mean values with different letters in the bar are significantly different $(P<0.05)$ according to Duncan's new MRT. The ranitidine group, $50 \mathrm{mg} / \mathrm{kg}$ b.w. ranitidine treatment dose; the LLTP group, $50 \mathrm{mg} / \mathrm{kg}$ b.w. flavonoid extract of lotus leaf dose; and the HLTP group, $100 \mathrm{mg} / \mathrm{kg}$ b.w. flavonoid extract of lotus leaf. (a) nNOS. (b) eNOS. (c) iNOS.

central nervous system, and protect the heart and cerebral vessels [39]. Astragalin has analgesic, anti-inflammatory, and lipid-lowering effects, as well as the ability to repair damaged DNA, and exerts inhibitory effects on the generation of TNF- $\alpha$, IL- $1 \beta$, and IL-6 [40]. Phloridzin has multiple important biological activities, such as reducing blood sugar, improving memory, and antioxidation and anticancer effects, and has been used in the development of new drugs and natural health foods [41]. Quercetin possesses antioxidation, anti-inflammation, and hypotensive functions and enhances capillary resistance [42]. FELL contains relatively high amounts of kaempferitrin and hyperoside, which are the most active constituents in FELL, and additionally, FELL is also beneficial because of the astragalin, phloridzin, and quercetin it contains. The combined effect of these five substances is responsible for the prevention of gastric injury.

Lotus leaf, as a commonly used traditional Chinese medicine or health food, has been widely used in clinical and life, including its protective effect on stomach. However, lotus leaf contains more components, and the relationship between lotus leaf components and efficacy has been lacking of relevant studies. In this study, flavonoids were extracted from lotus leaf to evaluate their protective effect on alcoholinduced gastric injury. FELL has been proven to have an effect on alcohol-induced gastric injury by observing the status of gastric juice, the appearance and the pathological morphology of gastric tissue, the serum level of related indices and inflammatory cytokines, and the expressions of related mRNA in the gastric tissue. It has a good inhibitory 
effect, which is attributed to the antioxidant capacity. Through component analysis, FELL was determined to contain five active bioactive substances, whose combined effects constituted the inhibitory effect of FELL on gastric injury. This study confirmed that flavonoids, one of the main active substances in lotus leaf, have gastroprotective effect, which is the same as the experience of using lotus leaf to protect the stomach. However, this study clarified the mechanism relationship between its components and efficacy, laying a foundation for further study of the role of lotus leaf. Thus, FELL is an active substance with a good gastroprotective effect. However, this study is based on a basic experimental model. In the future, additional experimental research is warranted to elaborate on the molecular biological mechanism.

\section{Data Availability}

No data were used to support this study.

\section{Conflicts of Interest}

The authors declare no conflicts of interest.

\section{Authors' Contributions}

Yi Chen and Qin Li contributed equally to this work. Yi Chen and Qin Li performed the majority of the experiments and wrote the manuscript. Zhiping Kuang, Xin Zhao, and Ruokun Yi contributed to the data analysis. Xiaowei He and Guangjing Feng designed and supervised the study and read the final manuscript.

\section{Acknowledgments}

This research was funded by the Chongqing Scientific Research Institute Performance Incentive Guidance Project (cstc2018jxjlX0003) and Funds for Construction of Chongqing Collaborative Innovation Center for Functional Food in Chongqing University of Education, China.

\section{References}

[1] J. Zhang, X. Sheng, and L. Jiang, "The dewetting properties of lotus leaves," Langmuir, vol. 25, no. 3, pp. 1371-1376, 2009.

[2] M.-Z. Zhu, W. Wu, L.-L. Jiao, P.-F. Yang, and M.-Q. Guo, "Analysis of flavonoids in lotus (Nelumbo nucifera) leaves and their antioxidant activity using macroporous resin chromatography coupled with LC-MS/MS and antioxidant biochemical assays," Molecules, vol. 20, no. 6, pp. 10553-10565, 2015.

[3] D.-B. Lee, D.-H. Kim, and J.-Y. Je, "Antioxidant and cytoprotective effects of lotus (Nelumbo nucifera) leaves phenolic fraction," Preventive Nutrition and Food Science, vol. 20, no. 1, pp. 22-28, 2015.

[4] J. B. Boreyko and C. H. Chen, "Restoring superhydrophobicity of lotus leaves with vibration-induced dewetting," Physical Review Letters, vol. 103, no. 17, Article ID 174502, 2009.
[5] M. Li and Z. Xu, "Quercetin in a lotus leaves extract may be responsible for antibacterial activity," Archives of Pharmacal Research, vol. 31, no. 5, pp. 640-644, 2008.

[6] Y. Guo, X. Chen, J. Qi, and B. Yu, "Simultaneous qualitative and quantitative analysis of flavonoids and alkaloids from the leaves ofNelumbo nuciferaGaertn. using high-performance liquid chromatography with quadrupole time-of-flight mass spectrometry," Journal of Separation Science, vol. 39, no. 13, pp. 2499-2507, 2016.

[7] M. Zhu, T. Liu, C. Zhang, and M. Guo, "Flavonoids of Lotus (Nelumbo nucifera) seed embryos and their antioxidant potential," Journal of Food Science, vol. 82, no. 8, pp. 1834-1841, 2017.

[8] S. G. Deng, Z. Y. Deng, and L. Huang, "Study on the antioxidative activity of flavonoids extracted from lotus leaves in vitro," Food Science and Technology, vol. 31, no. 17, pp. 274-276, 2006.

[9] A. G. Huang, H. F. Shi, H. Wei, R. J. Dong, and W. J. Zhou, “A comparative study on blood lipid regulatory function between flavonoids and alkaloids from lotus leaf," Culinary Science Journal of Yangzhou University, vol. 23, no. 3, pp. 23-25, 2006.

[10] H. G. Chen, Y. G. Yu, and Q. X. Zeng, "Development of healthy beverage of lotus leaves," Food and Machinery, vol. 2002, no. 2, p. 38, 2002.

[11] S. R. Jin, Z. Xu, J. H. Lei, Z. L. Hu, and L. F. Yao, "Study on flavonoid ultrasonic extraction from lotus leaf," Food Science and Technology, vol. 32, no. 10, pp. 97-99, 2007.

[12] P. M. Liu, D. Shailendrasing, N. S. Luo, Z. B. Huang, Y. Q. Lin, and J. F. Wang, "Alcohol intake and stroke in Eastern Asian men: a systemic review and meta-analysis of 17 prospective cohort studies," National Medical Journal of China, vol. 90, no. 40, pp. 2834-2838, 2010.

[13] V. Kuchipudi, K. Hobein, A. Flickinger, and F. L. Iber, "Failure of a 2-hour motivational intervention to alter recurrent drinking behavior in alcoholics with gastrointestinal disease," Journal of Studies on Alcohol, vol. 51, no. 4, pp. 356-360, 1990.

[14] M. R. Knoll, C. B. Kölbel, S. Teyssen, and M. V. Singer, "Action of pure ethanol and some alcoholic beverages on the gastric mucosa in healthy humans: a descriptive endoscopic study," Endoscopy, vol. 30, no. 3, pp. 293-301, 1998.

[15] R. Nordmann, C. Ribière, and H. Rouach, "Implication of free radical mechanisms in ethanol-induced cellular injury," Free Radical Biology and Medicine, vol. 12, no. 3, pp. 219-240, 1992.

[16] C. Kasinathan, P. Sundaram, B. L. Slomiany, V. L. N. Murty, and A. Slomiany, "Calcium transport and calcium activated ATPase activity in microsomal vesicles of rat gastric mucosa," International Journal of Biochemistry, vol. 25, no. 12, pp. 1807-1813, 1993.

[17] H. L. Yang, J. J. Wu, and J. W. Shi, "Protective effect on gastrointestinal mucosa of scalded rat by polygonum cuspidatum glycosides," Asia-Pacific Traditional Medicine, vol. 4, no. 7, pp. 23-25, 2008.

[18] A. M. Knab, D. C. Nieman, N. D. Gillitt et al., "Effects of a flavonoid-rich juice on inflammation, oxidative stress, and immunity in elite swimmers: a metabolomics-based approach," International Journal of Sport Nutrition and Exercise Metabolism, vol. 23, no. 2, pp. 150-160, 2013.

[19] N. Yoshimizu, Y. Otani, Y. Saikawa et al., "Anti-tumour effects of nobiletin, a citrus flavonoid, on gastric cancer include: antiproliferative effects, induction of apoptosis and cell cycle deregulation," Alimentary Pharmacology and Therapeutics, vol. 20, no. S1, pp. 95-101, 2004. 
[20] O. Coskun, A. Ocakci, T. Bayraktaroglu, and M. Kanter, "Exercise training prevents and protects streptozotocin-induced oxidative stress and $\beta$-cell damage in rat pancreas," The Tohoku Journal of Experimental Medicine, vol. 203, no. 3, pp. 145-154, 2004.

[21] F. Li, D.-Y. Lu, Q. Zhong et al., "Lactobacillus fermentum HFY06 reduced CCl4-induced hepatic damage in Kunming mice," RSC Advances, vol. 10, no. 1, pp. 1-9, 2020.

[22] C. Li, G. Huang, F. Tan, X. Zhou, J. Mu, and X. Zhao, "In vitro analysis of antioxidant, anticancer, and bioactive components of Apocynum venetum tea extracts," Journal of Food Quality, vol. 2019, Article ID 2465341, 13 pages, 2019.

[23] W. Y. Chey, "Alcohol and gastric mucosa," Digestion, vol. 7, no. 3-4, pp. 239-251, 1972.

[24] Y. Wu, Y. Wang, and X. Nabi, "Protective effect of Ziziphora clinopodioides flavonoids against $\mathrm{H}_{2} \mathrm{O}_{2}$-induced oxidative stress in HUVEC cells," Biomedicine \& Pharmacotherapy, vol. 117, p. 109156, 2019.

[25] P. L. Peghini, P. O. Katz, and D. O. Castell, "Ranitidine controls nocturnal gastric acid breakthrough on omeprazole: a controlled study in normal subjects," Gastroenterology, vol. 115, no. 6, pp. 1335-1339, 1998.

[26] J. Zhang, D.-Y. Lu, Y. Yuan et al., "Liubao Insect tea polyphenols prevent $\mathrm{HCl}$ /ethanol induced gastric damage through its antioxidant ability in mice," RSC Advances, vol. 10, no. 9, pp. 4984-4995, 2020.

[27] K. H. McDonough, "Antioxidant nutrients and alcohol," Toxicology, vol. 189, no. 1-2, pp. 89-97, 2003.

[28] Y. Qian, J. Zhang, X. Fu et al., "Preventive effect of raw Liubao tea polyphenols on mouse gastric injuries induced by $\mathrm{HCl}$ / ethanol via anti-oxidative stress," Molecules, vol. 23, no. 11, p. 2848,2018

[29] Y. Zhou, F. Tan, C. Li et al., "White Peony (fermented Camellia sinensis) polyphenols help prevent alcoholic liver injury via antioxidation," Antioxidants, vol. 8, no. 11, p. 524, 2019.

[30] J. Liu, F. Tan, X. Liu, R. Yi, and X. Zhao, "Exploring the antioxidant effects and periodic regulation of cancer cells by polyphenols produced by the fermentation of grape skin by Lactobacillus plantarum KFY02," Biomolecules, vol. 9, no. 10, p. $575,2019$.

[31] B. Liu, X. Xiao, X. Zhou et al., "Effects of Lactobacillus plantarum CQPC01-fermented soybean milk on activated carbon-induced constipation through its antioxidant activity in mice," Food Science \& Nutrition, vol. 7, no. 6, pp. 2068-2082, 2019.

[32] X. Long, X. Zhao, W. Wang et al., "Protective effect of silkworm pupa oil on hydrochloric acid/ethanol-induced gastric ulcers," Journal of the Science of Food and Agriculture, vol. 99, no. 6, pp. 2974-2986, 2019.

[33] X. Zhao, P. Sun, G. Li, R. Yi, Y. Qian, and K.-Y. Park, "Polyphenols in Kuding tea help prevent $\mathrm{HCl} /$ ethanol-induced gastric injury in mice," Food \& Function, vol. 9, no. 3, pp. 1713-1725, 2018.

[34] S. Chen, X. Zhao, P. Sun, J. Qian, Y. Shi, and R. Wang, "Preventive effect of Gardenia jasminoides on $\mathrm{HCl} /$ ethanol induced gastric injury in mice," Journal of Pharmacological Sciences, vol. 133, no. 1, pp. 1-8, 2017.

[35] H. Suo, X. Zhao, Y. Qian et al., "Lactobacillus fermentum Suo attenuates $\mathrm{HCl} /$ ethanol induced gastric injury in mice through its antioxidant effects," Nutrients, vol. 8, no. 3, p. 155, 2016.

[36] B. Liu, X. Feng, J. Zhang, Y. Wei, and X. Zhao, "Preventive effect of Anji White tea flavonoids on alcohol-induced gastric injury through their antioxidant effects in kunming mice," Biomolecules, vol. 9, no. 4, p. 137, 2019.

[37] H. Suo, X. Feng, K. Zhu, C. Wang, X. Zhao, and J. Kan, "Shuidouchi (fermented soybean) fermented in different vessels attenuates $\mathrm{HCl} /$ ethanol-induced gastric mucosal injury," Molecules, vol. 20, no. 11, pp. 19748-19763, 2015.

[38] J. Wang and Q. Zhao, "Kaempferitrin inhibits proliferation, induces apoptosis, and ameliorates inflammation in human rheumatoid arthritis fibroblast-like synoviocytes," Phytotherapy Research, vol. 33, no. 6, pp. 1726-1735, 2019.

[39] S.-K. Ku, W. Zhou, W. Lee, M.-S. Han, M. Na, and J.-S. Bae, "Anti-inflammatory effects of hyperoside in human endothelial cells and in mice," Inflammation, vol. 38, no. 2, pp. 784-799, 2015.

[40] C. Li, M. Hu, S. Jiang et al., "Evaluation procoagulant activity and mechanism of astragalin," Molecules, vol. 25, no. 1, p. E177, 2020.

[41] M. M. A. Khalifa, A. G. Bakr, and A. T. Osman, "Protective effects of phloridzin against methotrexate-induced liver toxicity in rats," Biomedicine \& Pharmacotherapy, vol. 95, pp. 529-535, 2017.

[42] R. V. Patel, B. M. Mistry, S. K. Shinde, R. Syed, V. Singh, and H.-S. Shin, "Therapeutic potential of quercetin as a cardiovascular agent," European Journal of Medicinal Chemistry, vol. 155, pp. 889-904, 2018. 